PREPARED FOR THE U.S. DEPARTMENT OF ENERGY, UNDER CONTRACT DE-AC02-76CH03073

PPPL-3745

PPPL-3745

UC-70

Operation of the NSTX Thomson Scattering System

by

B.P. LeBlanc, R.E. Bell, D.W. Johnson, D.E. Hoffman,

D.C. Long, and R.W. Palladino

September 2002

NM|

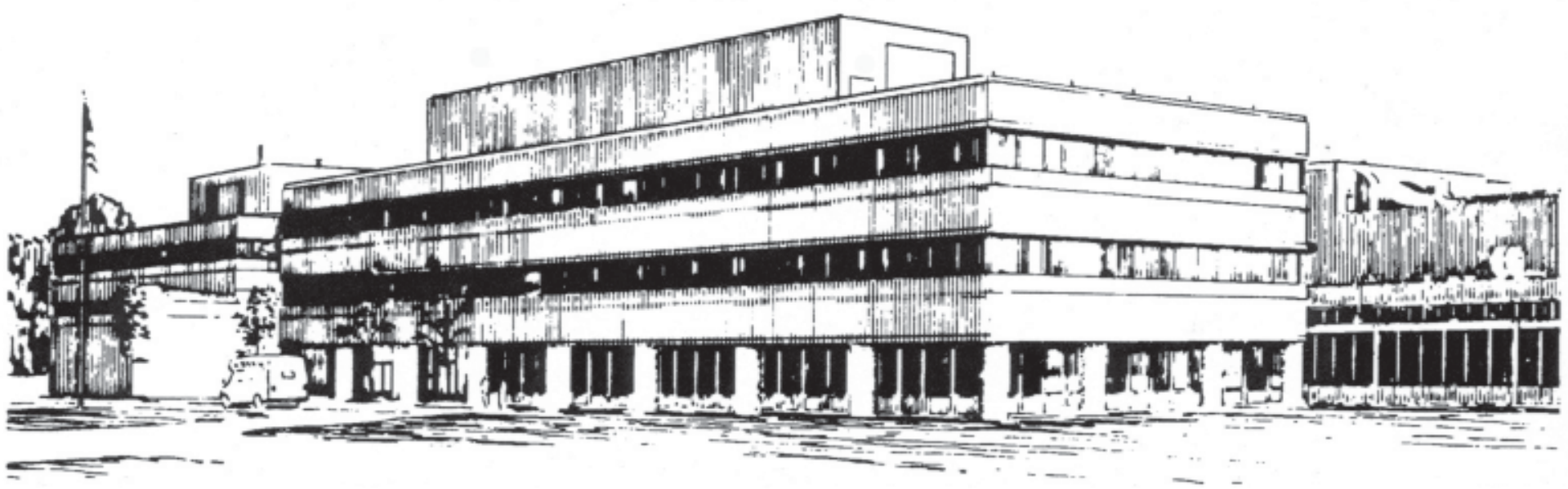

PRINCETON PLASMA PHYSICS LABORATORY PRINCETON UNIVERSITY, PRINCETON, NEW JERSEY 


\section{PPPL Reports Disclaimer}

This report was prepared as an account of work sponsored by an agency of the United States Government. Neither the United States Government nor any agency thereof, nor any of their employees, makes any warranty, express or implied, or assumes any legal liability or responsibility for the accuracy, completeness, or usefulness of any information, apparatus, product, or process disclosed, or represents that its use would not infringe privately owned rights. Reference herein to any specific commercial product, process, or service by trade name, trademark, manufacturer, or otherwise, does not necessarily constitute or imply its endorsement, recommendation, or favoring by the United States Government or any agency thereof. The views and opinions of authors expressed herein do not necessarily state or reflect those of the United States Government or any agency thereof.

\section{Availability}

This report is posted on the U.S. Department of Energy's Princeton Plasma Physics Laboratory Publications and Reports web site in Fiscal Year 2002. The home page for PPPL Reports and Publications is: http://www.pppl.gov/pub_report/

DOE and DOE Contractors can obtain copies of this report from:

U.S. Department of Energy

Office of Scientific and Technical Information

DOE Technical Information Services (DTIS)

P.O. Box 62

Oak Ridge, TN 37831

Telephone: (865) 576-8401

Fax: (865) 576-5728

Email: reports@adonis.osti.gov

This report is available to the general public from:

National Technical Information Service

U.S. Department of Commerce

5285 Port Royal Road

Springfield, VA 22161

Telephone: 1-800-553-6847 or

(703) 605-6000

Fax: (703) 321-8547

Internet: http://www.ntis.gov/ordering.htm 


\title{
Operation of the NSTX Thomson Scattering System
}

\author{
B.P. LeBlanc, R.E.Bell, D.W. Johnson, D.E. Hoffman, D.C. Long, and R.W. Palladino \\ Princeton Plasma Physics Laboratory, Princeton, NJ
}

\begin{abstract}
The NSTX multi-point Thomson scattering system has been in operation for nearly two years and provides routine $T_{e}(R, t)$ and $n_{e}(R, t)$ measurements. The laser beams from two 30-Hz Nd:YAG lasers are imaged by a spherical mirror onto 36 fiber-optics bundles. In the present configuration, the output ends of 20 of these bundles are instrumented with filter polychromators and avalanche photodiode detectors. In this paper, we discuss the laser implementation and the installed collection optics. We follow with examples of raw and analyzed data. We close with some comments about calibration.
\end{abstract}

\section{Introduction}

The NSTX Thomson scattering diagnostic is nearing its second year of operation and has become an important tool in the daily plasma operation, routinely providing time dependent radial profiles of the electron temperature, density, and pressure, in addition to temporal evolution of the line-integrated density. In order to obtain profile information from both the high and low field sides of the plasma, the system is designed to gather information on the horizontal midplane. Since high spatial resolution is ultimately desired, special attention was given to the design of a high throughput collection optics. The useful field of view spans ninety-three percent of the nominal plasma major radius in addition to the outer midplane scrape-off layer. In its present configuration, the system uses 20 spatial channels with two thirds of them dedicated to the low field side of the 
magnetic axis. We presently use two $30-\mathrm{Hz}$ lasers for a nominal time resolution of 16.7 ms $(60 \mathrm{~Hz})$. A phased implementation is in progress, which should reach 90-100 Hz time resolution and 36-45 spatial channels when completed. Based on its proven record, the Nd:YAG laser and discrete avalanche photodiodes (APD) combination was retained as light source and detector. ${ }^{1,2,3,45} \mathrm{We}$ have adopted a filter polychromator design by Carlstrom $^{6}$ et al. Each polychromator has six spectral channels: one centered at the laser wavelength, and five others spanning, with progressively wider bandwidth, the shorter wavelength side of the spectrum, down to $700 \mathrm{~nm}$. We have developed our own detection electronics. ${ }^{7}$ The latter includes low readout noise preamplifier modules, each with a temperature compensated, programmable high voltage power supply. Data acquisition is accomplished with sample and hold circuits with data from one spatial location multiplexed to one digitizer channel. This paper gives a brief review of the laser system implementation, describes the collection optics, and gives examples of experimental raw and analyzed data. Comments about calibration are added at the end.

\section{Laser system}

The lasers and ancillary instruments are located in a room outside the NSTX test cell and cantilevered off the massive structure of the radiation wall with steel framework. Part of the laser system can be seen schematically on Fig. 1. We are presently using two SpectraPhysics $30-\mathrm{Hz}$ YAG lasers, $L 1$ and $L 2$, with nominal energy per pulse $1.6 \mathrm{~J}$ and pulse width $8 \mathrm{~ns}$, operated at the fundamental wavelength $1064 \mathrm{~nm}$. These lasers include piezoelectrically driven mirrors, which maintain the aiming direction to within $50 \mu \mathrm{rad}$ over many hours. The beams have linear vertical polarization. The timing between the 
respective laser pulses can be set for $60-\mathrm{Hz}$ uniform time resolution, or set to time gaps as low as $0.4 \mathrm{~ms}$. The latter is a limit associated with the multiplexing electronics.

Prior to the plasma discharge, the lasers go through a two-minute warm-up sequence, during which the beams are terminated in the immediate vicinity of the lasers. Fast-action shutters, $F S$, release the beams for delivery to the vacuum vessel. The laser beams are combined, side-by-side horizontally with mirrors $M I$ through $M 4$. Laser beam sampling is done with a low reflectivity beam splitter, $B S$. The laser energy of the individual pulses is monitored in two ways: (1) with a Scientech pyro-electric joule meter, $J$, and (2) using a combination integrating sphere, $S$, and photodiode, $P D$, via a second beam splitter. The latter achieves a better temporal resolution than the inherently slower joule meter which can not resolve pulses closer than $10 \mathrm{~ms}$. Optical fibers $F O 1$ and $F O 2$ sample some light from each laser pulse, which is sent to the sample and hold circuitry for synchronization. Beyond the sampling point, both beams are expanded by a nominal factor of three through the same lens doublet, $B E$. Steering mirror $M 5$ directs the beams toward the NSTX test cell. A focusing doublet and an additional mirror bring the laser beams to focus at the nominal external plasma edge. After coming to proximity of NSTX's center stack, the laser beams continue toward the end of a long pumping duct where they enter a light trap, nine meters away from the focus point, $F P$ (see Fig. 2). The light trap is made of Schott KG-2 absorbing glass. The vertical polarization of the laser beams is maintained throughout. Alignment can be verified with a vacuum compatible movable target along the beam path and He-Ne reference laser beams. Fine tuning of the alignment is done using Rayleigh and Raman scattering. It is found that the alignment remains 
stable for periods of 2-3 months. These class IV laser beams remain enclosed over the full extent of the beam path.

\section{Collection optics}

In a previous paper, we showed that the back-scattering geometry is well matched to the physics requirement of the NSTX experiment. ${ }^{8}$ We retained the geometry, but the actual implementation differs from what was shown earlier. A top view of the collecting optics and its vicinity is shown in Fig. 2. The 16-cm diameter aperture stop, $A S$, is located 0.5 $\mathrm{cm}$ away from the external face of the fuse silica vacuum window, $V W$. The imaging element is a spherical pyrex first-surface spherical mirror, $P M$, with a protected gold coating, and spanning $72 \mathrm{~cm}$ horizontally and $40 \mathrm{~cm}$ vertically. Reducing the radius of curvature from the nominal $1 \mathrm{~m},{ }^{8}$ to $68 \mathrm{~cm}$ made it possible to install the mirror inside the toroidal field coil, $T F$. Tilting the optics slightly toward the laser beam, $L B$, made it possible to image not only the main plasma column but also the scrape-off layer. Some of the fiber bundles view beyond the nominal plasma edge, $P E$. Only one fiber bundle, $F B$, is shown for clarity, but 36 bundles are already in place. The imaged major radii, $R$, ranges from $R=0.27 \mathrm{~m}$, or $0.09 \mathrm{~m}$ from the center stack, $C S$, to $R=1.59 \mathrm{~m}$ corresponding to the antenna Faraday shield. The output ends of the fibers are mechanically assembled such that the bundles could be divided in the future to increase the spatial resolution. We elected not to use corrector plates, ${ }^{8}$ because ray-tracing analysis showed adequate imaging by the mirror alone. The combination of large aperture and curvature combined with unavailability of well-matched high transmission NIR polarizing material made it impractical to install a polarizer into the collection optics. Fortunately, the optics collects light in the near infrared, a spectral region where the 
background radiation is relatively low and a polarizer is not needed to reduce the plasma light contribution. Depolarization effects on the Thomson scattered light are negligible for temperatures below $9 \mathrm{keV},{ }^{9}$ which is more than twice the highest temperature reached in NSTX.

\section{Experimental Data}

Each APD is connected to a preamplifier, which provides a "fast" and a "slow" electronic output. Details of the electronics can be found elsewhere. ${ }^{7}$ The fast channel is designed to respond on the laser time scale and produces an output that is background subtracted. The slow channel responds on the microsecond time scale. While the fast output is used for laser scattering measurement, the slow output is used to measure the plasma background light and also to perform calibrations. An example of raw data signals is shown in Fig. 3. We can see, top panel, the time evolution of the fast output for an APD sampling light through a $6.8 \mathrm{~nm}$ wide filter centered at $1024 \mathrm{~nm}$, for a spatial channel located about midway between the magnetic axis and the Faraday shield. In this case, the two lasers are interwoven in time providing a $60 \mathrm{~Hz}$ time base. The sample and hold electronics acquires background light data between laser pulse at a nominal rate of $2 \mathrm{kHz}$, hence data points can be seen between laser pulses. The scattered signal $\mathrm{S} / \mathrm{N}$ reaches values in excess of 50. The two lasers deliver a slightly different energy to the vacuum vessel, resulting in an amplitude modulation. The slow ouput, bottom panel, shows a smooth time evolution until a reconnection, which occurred at $0.44 \mathrm{~s}$. The Thomson scattering signal, top panel, disappears after that time point, as a result of the quenching of the plasma.

Figure 4 shows the standard Thomson scattering analysis output for a neutral beam heated discharge. One can see in panels (a), (b) and (c) respectively, spatial overlays of 
the $T_{e}(R, t)$ and $n_{e}(R, t)$ and, the $p_{e}(R, t)$ profiles. Panel (d) shows the time evolutions of the central electron $T_{e o}$ and line-integrated density, $n_{e} l$. Although 37 time points exist, only 5 are shown for clarity. They are labeled 1 through 5 on the profile panels and time evolution panel and correspond to times $0.160,0.177,0.293,0.360$, and $0.410 \mathrm{~s}$. Traces from a Mirnov coil, MHD, neutral beam heating power, NBI, and deuterium Balmer light, $\mathrm{D} \alpha$, are shown for reference. An H-mode transition occurs between time points 1 and 2. Looking at the density profiles, we see that the earlier profile is centrally peaked and monotonic, while a steepening of the edge density profile is initiated after the transition. Time point 3 was obtained just after an MHD event, which can be seen on the Mirnov signal at $0.29 \mathrm{~s}$. A decrease of the central $T_{e}$ and a broadening of its profile is observed. By that time the density profile has flattened and shows "ears". A large density gradient now exists in the edge region. Time points 4 and 5 were taken at the start of the high power phase and at peak $T_{e}$ respectively. During that phase, the density profile increases uniformly. The measured edge gradient is $\leq 1.4 \times 10^{13} \mathrm{~cm}^{-4}$. The plasma edge moves in by about $3 \mathrm{~cm}$ for time point 5 . We see that, while the overall density continues increasing, the central region has filled in and shows a broadly localized maximum that is outward shifted. At time point 4 , the $T_{e}$ profile shows some internal steepening of the its profile. That later feature is still somewhat visible at time point 5 , when $T_{e}$ slightly exceeds $1.2 \mathrm{keV}$. In panel (c), we see the pressure profiles for the five time points. We see a progression toward higher pressures, as the Shafranov shift becomes visible, with peak value nearing $11 \mathrm{kPa}$. 


\section{Absolute Calibration}

Because of the distributed nature of the detection system, an extensive array of calibrations is required. The fundamental calibration procedures are a Rayleigh scattering and a spectral calibration. The availability of calibrated pressure gauges in the 1-2 T range makes it possible to absolutely calibrate the system. While the Rayleigh scattering is done using the amplifier fast output, the spectral calibration is done with the slow output. A calibration is then needed to link the fast and the slow channels of each APD. A gain calibration is also performed, which measures the APD gain as a function of the applied high voltage.

The number of photoelectrons detected is typically $>10^{4}$ making the photon statistics a minor contributor to error bars compared to systematic errors. The error bars are dominated by the uncertainty in the calibration of the reference detector used in the spectral calibration of the polychromators. The absolutely calibrated Thomson-scattering determinations of $n_{e} l$ compare well with FIR-laser interferometric measurements, typically to within 5\%. It is worthwhile mentioning here that first-principle estimates based on our knowledge of the electronic transfer function, the etendue and the transmission reproduce the Rayleigh scattering measurements to within $20 \%$.

\section{Conclusion}

The NSTX Thomson scattering system is now operational and provides routinely valuable electron temperature, density, pressure profiles and line-integrated density. In its current implementation, the system has 20 spatial channels and two $30-\mathrm{Hz}$ lasers. This implementation is about halfway from the design goal of $90-100 \mathrm{~Hz}$ and $36-45$ spatial 
channels. The system is absolutely calibrated. This work supported by U.S. DOE contract DE-AC02-76CH03073.

\footnotetext{
${ }^{1}$ H. Rohr, et al., IPP Report III/121B, July 1987.

${ }^{2}$ H. Murmann et al., Rev. Sci. Instrum. 63, 4941 (1992).

${ }^{3}$ T.N. Carlstrom et al., Rev. Sci. Instrum. 63, 4901 (1992).

${ }^{4}$ P. Pizzolati et al., Rev. Sci. Instrum. 63, 4403(1992).

${ }^{5}$ K. Narihara et al., Rev. Sci. Instrum. 65, 4607 (1995).

${ }^{6}$ T.N. Carlstrom, et al., Rev. Sci. Instrum. 61, 2855 (1990).

${ }^{7}$ D.W. Johnson, B.P. LeBlanc, and D. Long, Rev. Sci. Instrum, 72, 1129 (2001).

${ }^{8}$ D.W. Johnson, N. Bretz, B. LeBlanc, et al., Rev. Sci. Instrum., 70, 776 (1999).

${ }^{9}$ O. Theimer and W. Hicks, Phys. Fluids., 11,1045, (1968)
} 


\section{Figure Captions.}

Figure 1: Beams from Nd:YAG lasers L1 and L2 are combined side by side with mirrors M1-M4. Two fast shutters FS release the beam for delivery after warm up. Energy monitoring is done through beam splitters BS. The main beams enter expanding doublet BE before being reflected off mirror M5 toward NSTX. See text for details.

Figure 2: Spherical mirror PM images laser path onto surface IM, where fiber bundle FB collects light. Only one out of 36 bundles is shown. Aperture stop AS located next to viewing window VW. Optics sees main plasma and scrape-off layer. See text for details.

Figure 3: Top panel: raw data from preamplifier fast output. Two 30-Hz lasers intervened in time. Bottom panel: Background light measurement from slow preamplifier output. See text for details.

Figure 4: Analyzed data for a NBI heated discharge. Time slice overlays of $T_{e}(R, t)$, $n_{e}(R, t)$ and $p_{e}(R, t)$ are seen in panels $(\mathrm{a}),(\mathrm{b})$, and (c). Temporal evolution is seen in panel (d). Time points $0.160,0.177,0.293,0.360$, and $0.410 \mathrm{~s}$ are labeled $1-5$. See text for details. 
7
0
0
0
0
0
0
0
0
0
0
0
0
0
0
0
0
0

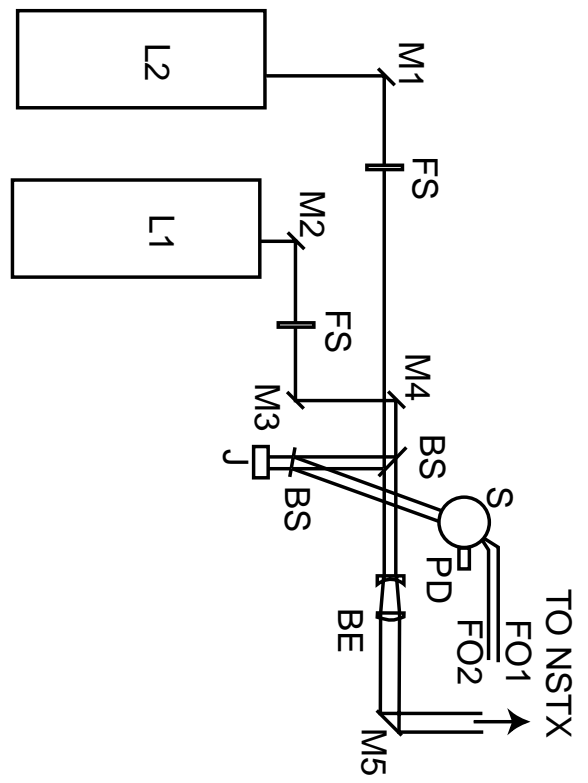


7
7
09
0
00
0
0
0
0
0
0
0
0
0
0
0
0
0

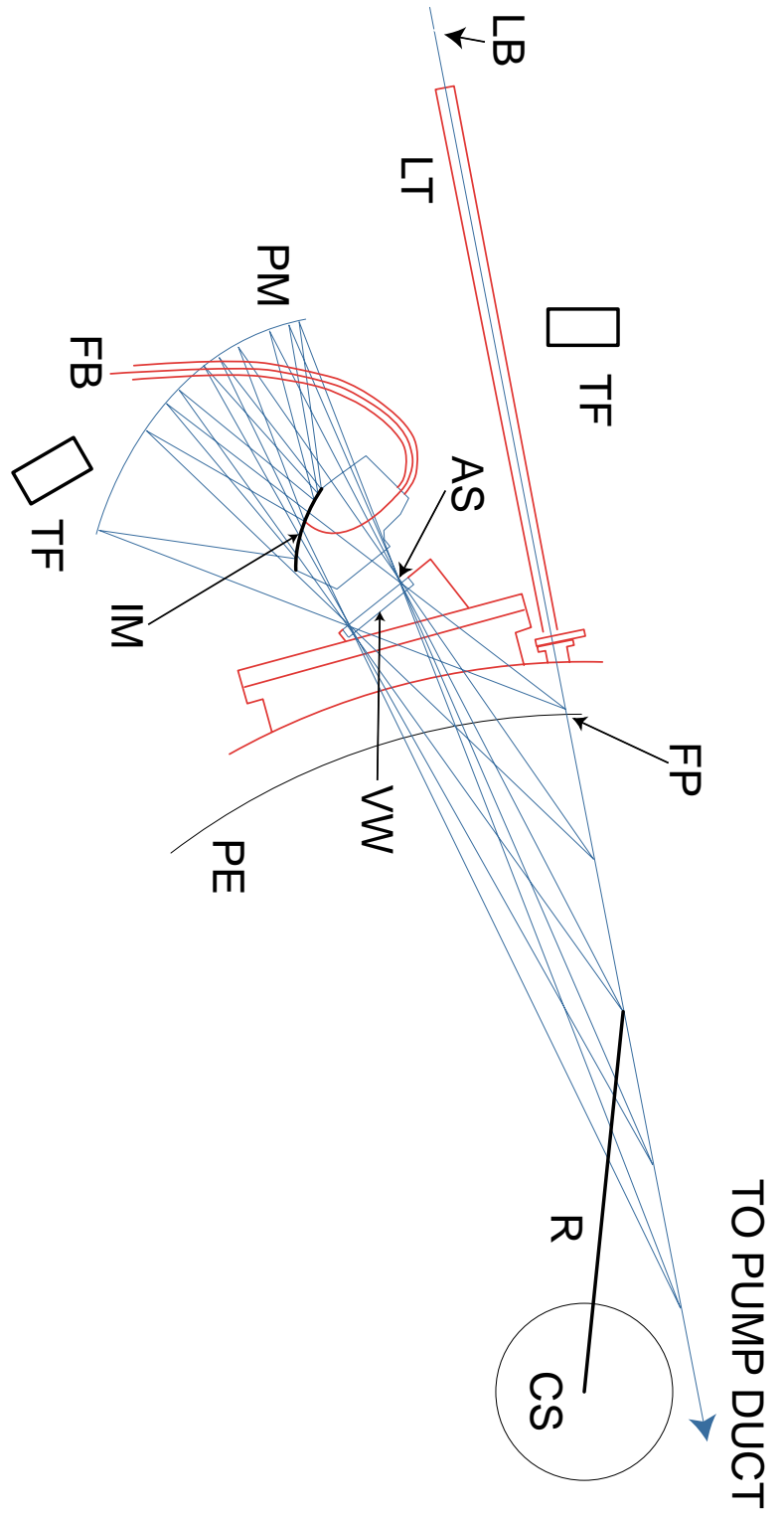




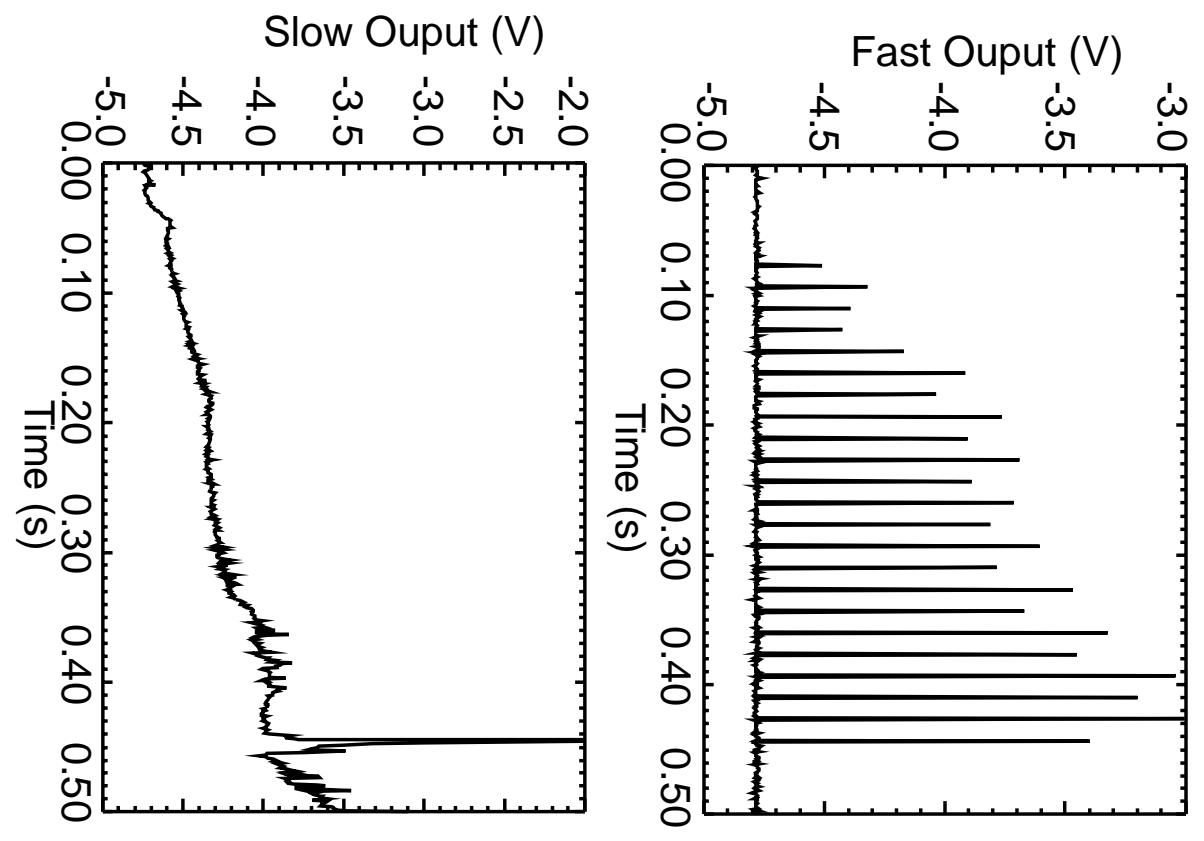


7
70
0
0
0
0
0
0
0
0
0
0
0
2
0
0
0
0
0
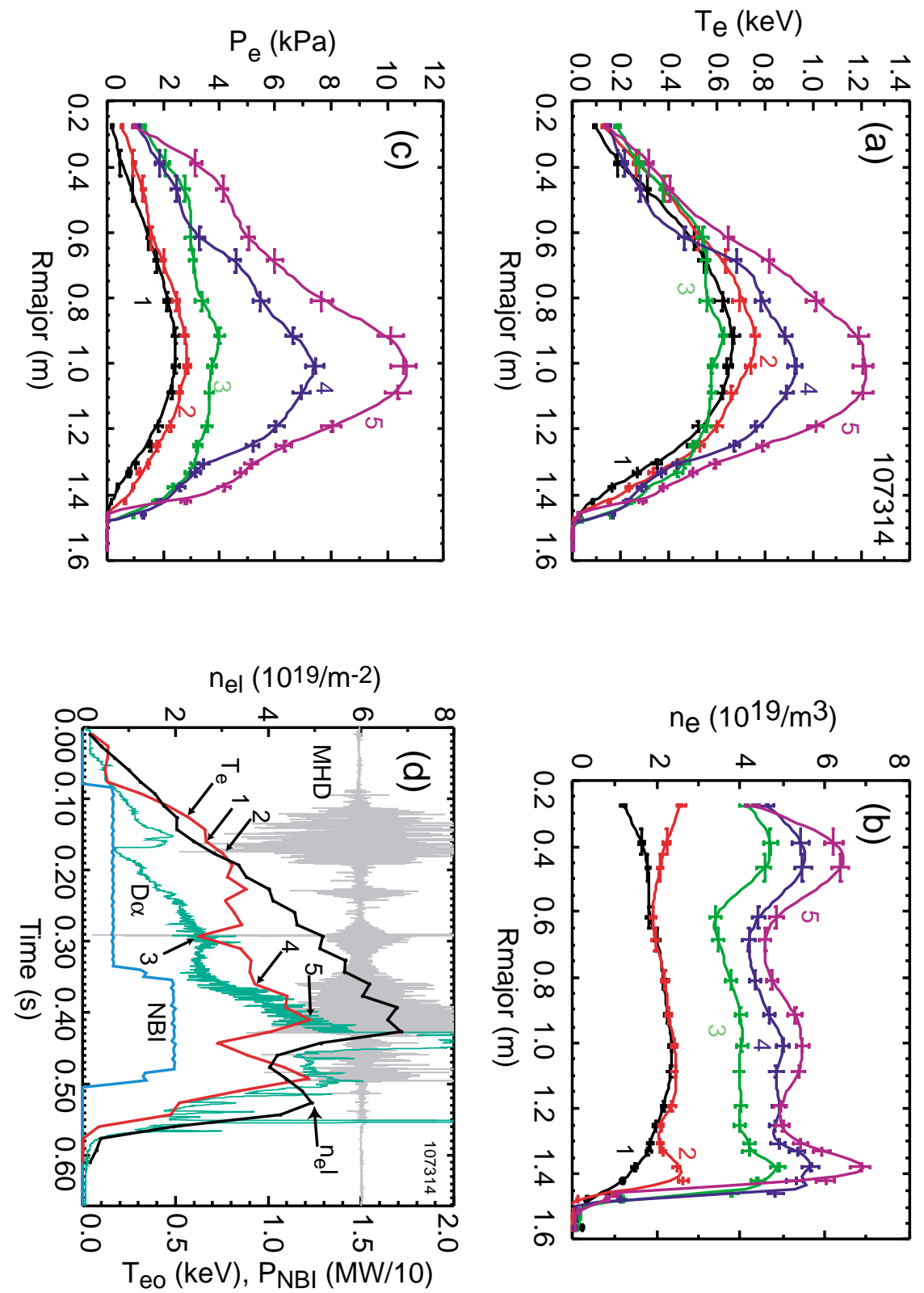


\section{External Distribution}

Plasma Research Laboratory, Australian National University, Australia

Professor I.R. J ones, Flinders University, Australia

Professor J oão Canalle, Instituto de Fisica DEQ/IF - UERJ , Brazil

Mr. Gerson O. Ludwig, Instituto Nacional de Pesquisas, Brazil

Dr. P.H. Sakanaka, Instituto Fisica, Brazil

The Librarian, Culham Laboratory, England

Library, R61, Rutherford Appleton Laboratory, England

Mrs. S.A. Hutchinson, JET Library, England

Professor M.N. Bussac, Ecole Polytechnique, France

Librarian, Max-Planck-Institut für Plasmaphysik, Germany

J olan Moldvai, Reports Library, MTA KFKI-ATKI, Hungary

Dr. P. Kaw, Institute for Plasma Research, India

Ms. P.J . Pathak, Librarian, Insitute for Plasma Research, India

Ms. Clelia De Palo, Associazione EURATOM-ENEA, I taly

Dr. G. Grosso, Instituto di Fisica del Plasma, Italy

Librarian, Naka Fusion Research Establishment, J AERI, J apan

Library, Plasma Physics Laboratory, Kyoto University, J apan

Research Information Center, National Institute for Fusion Science, J apan

Dr. O. Mitarai, Kyushu Tokai University, J apan

Library, Academia Sinica, Institute of Plasma Physics, People's Republic of China

Shih-Tung Tsai, Institute of Physics, Chinese Academy of Sciences, People's Republic of China

Dr. S. Mirnov, TRINITI, Troitsk, Russian Federation, Russia

Dr. V.S. Strelkov, Kurchatov Institute, Russian Federation, Russia

Professor Peter Lukac, Katedra Fyziky Plazmy MFF UK, Mlynska dolina F-2, Komenskeho Univerzita, SK-842 15 Bratislava, Slovakia

Dr. G.S. Lee, Korea Basic Science Institute, South Korea

Mr. Dennis Bruggink, Fusion Library, University of Wisconsin, USA

Institute for Plasma Research, University of Maryland, USA

Librarian, Fusion Energy Division, Oak Ridge National Laboratory, USA

Librarian, Institute of Fusion Studies, University of Texas, USA

Librarian, Magnetic Fusion Program, Lawrence Livermore National Laboratory, USA

Library, General Atomics, USA

Plasma Physics Group, Fusion Energy Research Program, University of California at San Diego, USA

Plasma Physics Library, Columbia University, USA

Alkesh Punjabi, Center for Fusion Research and Training, Hampton University, USA

Dr. W.M. Stacey, Fusion Research Center, Georgia Institute of Technology, USA

Dr. J ohn Willis, U.S. Department of Energy, Office of Fusion Energy Sciences, USA

Mr. Paul H. Wright, Indianapolis, Indiana, USA 
The Princeton Plasma Physics Laboratory is operated by Princeton University under contract with the U.S. Department of Energy.

\author{
Information Services \\ Princeton Plasma Physics Laboratory \\ P.O. Box 451 \\ Princeton, NJ 08543
}

Phone: 609-243-2750

Fax: 609-243-2751

e-mail: pppl_info@pppl.gov

Internet Address: http://www.pppl.gov 